\title{
Research Roadmap for Future Internet Enterprise Systems
}

\author{
Gérald Santucci \\ Networked Enterprise \& Radio Frequency Identification (RFID), INFSO DG, EC \\ B -1049 Brussels, Belgium \\ infso-desk@ec.europa.eu
}

\begin{abstract}
In this presentation, we will introduce and explain a research roadmap for Future Internet enterprise systems. This research roadmap has been developed by the community of scientists, developers and other stakeholders in the context of the "Future Internet Enterprise Systems" cluster, managed by the "Internet of Things and Networked Enterprise" unit of the Information Society and Media General-Directorate of the European Commission.
\end{abstract}

Keywords: research roadmap; Future Internet; enterprise systems.

\section{Brief Biography}

Gérald Santucci has been working in the Information Society and Media DirectorateGeneral of the European Commission since February 1986. In March 2007, he was appointed Head of the Unit Networked Enterprise \& Radio Frequency Identification (RFID). The unit's portfolio includes some $40 \mathrm{R} \& \mathrm{D}$ projects, grouped around two clusters, which address the development of ICT-based systems supporting the Future Internet Networked Enterprise and the shift from contactless technologies towards the "Internet of Things".

The adoption by the European Commission, in March 2007, of a Communication on RFID has constituted a first milestone towards the achievement of a European policy framework regarding RFID. Work underway includes: the continuous monitoring of a Commission Recommendation on the implementation of privacy and data protection principles in RFID-enabled applications, with special emphasis placed on privacy impact assessment and RFID signs/logos; a Commission Communication on the Internet of Things, which covers fourteen different lines of action, in particular governance, privacy and data protection, and the 'right to the silence of the chips'; and a Mandate to European Standardization Organizations on privacy and security aspects of RFID. Gérald is the acting chairman of the Expert Group on the Internet of Things, composed of some 50, stakeholders from Law, Economics and Technology, which is tasked with advising the European Commission on Internet of Things evolution and associated public policy challenges. In addition, Gérald is highly committed to develop and strengthen cooperation with Europe's international partners, such as Japan, China, Korea, U.S., Brazil and India, in order to promote the exchange of information and best practices and the definition of global or harmonized standards and regulations in the emerging field of Internet of Things. 
Over the years, Gérald has gained extensive experience in the activities of the Directorate-General through his involvement in research management, including heading the Unit "Applications relating to Administrations" (i.e., eGovernment) 1999-2002, the Unit "Trust and Security" 2003, and "ICT for Enterprise Networking" 2004-2006. During the period from 1986 to 1989, Gérald managed the preparatory work that led to the AIM (Advanced Informatics in Medicine) exploratory action, which still exists today in the form of the ICT for Health unit of DG Information Society and Media. In 1991-1993, he was involved in the Uruguay Round Trade Negotiations with respect to Semiconductors (tariffs, rules of origin, direct investment) and drafted a Commission Communication on the European Telecommunications Equipment Industry.

In November 2008 Gérald Santucci received the Honourable Mention in the Asset Tracking Forum segment of the ID People Awards ceremony at the seventh ID WORLD International Congress in Milan. This recognition underlined Gérald's untiring efforts to drive forward and foster a coherent European approach to RFID that ensures common standards, harmonized legislation as well as compatible guidelines.

Gérald holds a Master's degree from the Institute for Political Studies in Paris, and a Ph.D. in Microeconomics from the University of Paris 12 Val-de-Marne. 